\title{
Biodiversity at risk in the Americas
}

\author{
Carlos A. Joly ${ }^{1,2 *}$ \\ ${ }^{1}$ Universidade Estadual de Campinas, Campinas, SP, Brasil \\ ${ }^{2}$ Plataforma Brasileira de Biodiversidade e Serviços Ecossistêmicos, Campinas, SP, Brasil \\ *Corresponding author: Carlos A. Joly,e-mail: cjoly@unicamp.br
}

At the end of March 2018, the Intergovernmental Platform for Biodiversity and Ecosystem Services (IPBES) launched the First Assessment on Biodiversity and Ecosystem Services for the Americas region. The conclusions of this colossal work, developed by about 100 experts over three years, are at least alarming.

The mainland of the Americas is the world's longest north-to-south landmass, and the distance between the northernmost point to the southernmost point is about $14,000 \mathrm{~km}$. Including the Caribbean the area is divided into 36 countries (Canada, United States, Mexico, Guatemala, Belize, Honduras, El Salvador, Nicaragua, Costa Rica, Panama, Antigua and Barbuda, Bahamas, Barbados, Cuba, Dominica, Dominican Republic, Grenada, Haiti, Jamaica, Saint Lucia, Saint Kitts and Nevis, Saint Vincent and the Grenadines, Trinidad and Tobago, French Guyana, Suriname, Guyana, Brazil, Venezuela, Colombia, Ecuador, Peru, Bolivia, Chile, Paraguay, Uruguay, Argentina).

The American continent, including the Caribbean, is one of the richest regions in the world in terms of biodiversity and ecosystem services, housing seven of the 17 megadiverse countries, the largest rainforest, and an unparalleled array of freshwater environments including rivers, lakes, dams and wetlands. Around 29 per cent of the world's seed plants, 35 per cent of mammals, 35 per cent of reptiles, 41 per cent of birds and 51 per cent of amphibians are found in the Americas, totaling over 122,000 species for those species groups alone. In addition it hosts over one third of the world's freshwater fish fauna, consisting of over 5,000 species. Conservatively, 33 per cent of the plants used by humans are found in the Americas.

The Americas is also a highly culturally and socioeconomically diverse region, home to 15 per cent of global languages. It is populated by over 66 million indigenous people whose cultures have persisted in all subregions and, in addition, by an exceptionally large proportion of new immigrants and descendants of immigrants, mainly from Europe, Asia and Africa. The cultural diversity of indigenous peoples and local communities in the Americas provides a plethora of knowledge and world views for managing biodiversity and nature's contributions to people in a manner consistent with cultural values promoting the respectful interaction of people with nature. This collective diversity provides many opportunities to develop world views compatible with sustainable uses of and respect for nature in a globalized world.

Socioeconomically, the region contains 2, US and Canada, of the 10 countries with the highest Human Development Index, as well as 1, Haiti, of the 30 countries with the lowest Human Development Index. Such heterogeneity makes it difficult to develop general conclusions that apply uniformly across all subregions.
We also have about $40 \%$ of the world's capacity to produce nature-based products, which are essential to guarantee food, water and energy security, pollinating services, climate regulation, as well as non-material services such as cultural continuity, spiritual and aesthetic. Considering only the terrestrial part of the continent, the value of these ecosystem services is estimated at US \$ 24.3 trillion, the equivalent of the GDP of all countries of the region.

However, both biodiversity and the ecosystem services that depend on it, are under tremendous pressure. At least $65 \%$ of services are declining, while $21 \%$ are declining very fast. About $1 / 4$ of the 14,000 species of well-known taxonomic groups are at risk of extinction, to a greater or lesser degree, in terrestrial, fresh water and marine environments.

Among the endemic species the threat of extinction can reach $40 \%$, in the case of the Caribbean species. On the continent as a whole, these losses are already affecting the ecosystem services associated with the provision and protection of water resources, as well as those associated with food production, including subsistence crops.

By 2005, the Millennium Ecosystem Assessment had already ignited the yellow light on the health of the planet's ecosystems. Unfortunately this warning has not been taken into account, and in the last two decades, since the end of the $20^{\text {th }}$ century, the problems only worsened.

Population growth, migration, climate change, economic growth model and the fragility of environmental governance are the main indirect anthropogenic factors that impact biodiversity and ecosystem services on the continent. The region's GDP has grown six times since 1960, which has meant an improvement in the quality of life of millions of inhabitants in the region, but unfortunately, due to the predatory model of economic growth, it also represented a disproportionate increase in the conversion and fragmentation of habitats, generally for unsustainable production of export commodities such as soybeans and meat.

In the Americas we find a diversity of governance models of biodiversity and ecosystem services, embedded in a myriad of socioeconomic and cultural realities. Many of them aim to reduce the pressures of environmental degradation factors. But for the most part environmental policy is subordinated to short-term economic policies, lacking the necessary integration for the implementation of a model of sustainable development that guarantees an improvement in life quality without the predatory exploitation of biodiversity and ecosystem services. Short term plans to reduce inequity, for example, often compromise resources from the next generations. 
Joly, C.A.

The report also identifies policy decisions that, if taken immediately, can reverse this alarming picture. For example, large-scale restoration of degraded areas, such as that proposed by Brazil in the Paris Agreement, as well as changing production/consumption patterns, adopting less caloric diets and avoiding food wastage.

But the most effective solution would be to put biodiversity and ecosystem services associated with life quality at the center of the economic development policies of Americas' countries.

All data figures mentioned in this manuscript are from:
Rice, J.; Seixas. C.S.; Zaccagnini, M.E.; Bedoya-Gaitán, M.; Valderrama, N.; Anderson, C.B.; Kalin-Arroyo, M.T.; Bustamante, M.; Cavender-Bares, J.; Diaz-de-León, A..; Fennessy, M.S.; GarcíaMarquez, J.R.; Garcia, K.; Helmer, E.H.; Herrera, B.; Klatt, B.; Ometo, J.P.; Rodriguez-Osuna, V.; Scarano, F.R,; Schill, S. \& Farinaci, J.S. 2018. Summary for policymakers of the regional assessment report on biodiversity and ecosystem services for the Americas of the Intergovernmental Science-Policy Platform on Biodiversity and Ecosystem Services/IPBES, IPBES Secretariat, Bonn, Germany. Available at https://www.ipbes.net/sites/default/files/downloads/ ipbes-6-5_en.pdf 